\title{
Usefulness of accessible imaging methods in thyroid nodules with indeterminate cytology
}

\author{
Pedro Weslley Rosario, Tiara Grossi Rocha and Gabriela Franco Mourão \\ Santa Casa de Belo Horizonte, Minas Gerais, Brazil \\ Correspondence should be addressed to P W Rosario: pedrowsrosario@gmail.com
}

\begin{abstract}
In thyroid nodules (TN) submitted to fine-needle aspiration (FNA), Bethesda categories III and IV are considered 'indeterminate' cytology. This result corresponds to $10-25 \%$ of all FNAs and the risk of malignancy (RoM) ranges from $10 \%$ to $30 \%$ for category III and from $15 \%$ to $40 \%$ for category IV. This review analyzed the practical applicability of accessible imaging method in the management of patients with cytologically indeterminate TN $>1 \mathrm{~cm}$ (ITN). When ITN are highly suspicious on ultrasonography (US), the RoM supports surgical indication even in the absence of additional tests. The same can be applied to ITN of intermediate suspicion but with elevated stiffness on elastography. Follow-up without additional tests is acceptable in the case of ITN with low-risk cytology and low-suspicion appearance on US and elastography (if obtained). In the case of ITN without highly suspicious US appearance, ${ }^{123}$ I scintigraphy may be obtained in patients with TSH $<1-1.5$ $\mathrm{mIU} / \mathrm{L}$ to rule out hyperfunctioning nodules before requesting diagnostic methods that are more expensive and less accessible. In addition, in ITN with not very suspicious US appearance, 18FDG-PET may be obtained. If this method does not reveal nodular uptake, the risk of the nodule corresponding to a macrocarcinoma is sufficiently low in order to allow follow-up. The positive predictive value of focal nodular uptake on ${ }^{18} \mathrm{FDG}$-PET depends on the pre-test RoM, cytological findings, and maximum SUV. There is currently no evidence for the use of CT, MRI or imaging using $99 \mathrm{mTC}-\mathrm{MIBI}$ to define the nature of ITN.
\end{abstract}

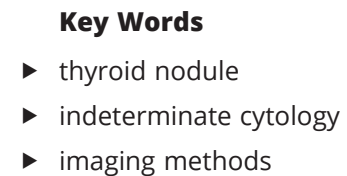

Endocrine-Related Cancer (2021) 28, R1-R9

\section{Introduction}

Thyroid nodules are common in the adult population. Initial assessment consists of excluding functionality and defining whether there is an indication for fineneedle aspiration (FNA). Usually, autonomous nodules, purely cystic nodules or nodules less than $0.5 \mathrm{~cm}$ do not require FNA. This procedure may be indicated in nodules with a diameter between 0.5 and $1 \mathrm{~cm}$ and a suspicion for malignancy on ultrasonography (US) depending on their location, suspicion of metastases, family or personal history, and need for surgery if they correspond to microcarcinomas (Gharib et al. 2016, Russ et al. 2017, Tessler et al. 2017, Pacini et al. 2018). For nodules larger than $1 \mathrm{~cm}$, the risk of malignancy (RoM) estimated by US defines the diameter that would indicate FNA (Perros et al. 2014, Gharib et al. 2016, Haugen et al. 2016, Russ et al. 2017, Tessler et al. 2017, Pacini et al. 2018, Giovanella et al. 2019).

In the case of nodules with an indication for FNA, cytology is classified using one of the known systems (Table 1). Traditionally, categories III (B-III) and IV (B-IV) of the Bethesda System (Ali \& Cibas 2018), Thy3 of the UK Royal College of Pathologists Classification System (Perros et al. 2014), and TIR3 of the Italian Reporting System (Pacini et al. 2018) are defined as 'indeterminate' cytology 
Table 1 Terminology and nomenclatures chemes for reporting thyroid cytopathology.

\begin{tabular}{|c|c|c|}
\hline \multicolumn{3}{|c|}{ System } \\
\hline $\begin{array}{l}\text { Royal College of Pathologists Classification System } \\
\text { (Perros et al. 2014) }\end{array}$ & $\begin{array}{l}\text { Italian Reporting System } \\
\text { (Pacini et al. 2018) }\end{array}$ & $\begin{array}{l}\text { Bethesda System } \\
\text { (Ali \& Cibas 2018) }\end{array}$ \\
\hline \multicolumn{3}{|c|}{ Categories } \\
\hline Thy 1: Non-diagnostic & TIR 1: Non-diagnostic & I: Non-diagnostic \\
\hline Thy 2: Non-neoplastic & TIR 2: Benign & II: Benign \\
\hline $\begin{array}{l}\text { Thy3a: Neoplasm possible - Cytological/nuclear } \\
\text { or architectural atypia }\end{array}$ & $\begin{array}{l}\text { TIR 3A: Indeterminate - } \\
\text { Low-risk lesions }\end{array}$ & $\begin{array}{l}\text { III: Atypia or follicular lesion of of } \\
\text { undetermined significance }\end{array}$ \\
\hline Thy3f: Neoplasm possible - Follicular neoplasms & $\begin{array}{l}\text { TIR 3B: Indeterminate - High-risk } \\
\text { lesions }\end{array}$ & $\begin{array}{l}\text { IV: Follicular neoplasm or suspicious } \\
\text { for a follicular neoplasm }\end{array}$ \\
\hline Thy4: Suspicious of malignancy & TIR 4: Suspicious of malignancy & v: Suspicious for malignancy \\
\hline Thy5: Malignant & TIR 5: Malignant & VI: Malignant \\
\hline
\end{tabular}

(Table 1). This result corresponds to approximately 10-25\% of all FNAs (Gharib et al. 2016, Pacini et al. 2018).

Although Bethesda category V (B-V) (Ali \& Cibas 2018), Thy4 (Perros et al. 2014) and TIR4 (Pacini et al. 2018) can also be considered indeterminate, we do not include them in this definition. The RoM of these categories is elevated and significantly higher than that expected for categories B-III and B-IV (Thy3, TIR3) (Perros et al. 2014, Gharib et al. 2016, Haugen et al. 2016, Ali \& Cibas 2018, Pacini et al. 2018). In addition, the management for category B-V (Thy4, TIR4) differs from that recommended for categories B-III and B-IV (Thy3, TIR3), and is very similar to or even the same as that recommended for category B-VI (Thy5, TIR5) (Gharib et al. 2016, Haugen et al. 2016, Ali \& Cibas 2018, Pacini et al. 2018). In the case of B-III cytology (Thy3a, TIR3A), the change of category in a new FNA or after revision by an experienced cytopathologist is common. For this reason, repetition of FNA or revision by an experienced cytopathologist is desirable in category B-III (Thy3a, TIR3A) before additional tests are carried out for the definition of management (Perros et al. 2014, Gharib et al. 2016, Haugen et al. 2016, Ali \& Cibas 2018, Pacini et al. 2018). Exceptions would be patients with an already defined surgical indication, even if the new result is benign, or individuals for whom observation will be the management, even if cytology remains indeterminate.

The RoM of nodules with indeterminate cytology generally ranges from $10 \%$ to $30 \%$ for category B-III (Thy3a, TIR3A) and from $15 \%$ to $40 \%$ for category B-IV (Thy3f, TIR3B) (Perros et al. 2014, Gharib et al. 2016, Haugen et al. 2016, Ali \& Cibas 2018, Pacini et al. 2018, Giovanella et al. 2019). Considering that FNA is indicated correctly, this RoM is too high to recommend the follow-up of all patients without any additional investigation. However, the opposite management, that is, thyroidectomy for all patients will result in many unnecessary surgeries.
Thus, parameters that refine the RoM for these nodules are important. These include imaging methods that are accessible in clinical practice, which are the focus of this review.

\section{Ultrasonography}

US should be performed on all individuals with thyroid nodules and the nodules should be categorized using one of the current ultrasonographic classifications. This information is also necessary for the indication of FNA (Perros et al. 2014, Gharib et al. 2016, Haugen et al. 2016, Russ et al. 2017, Tessler et al. 2017, Pacini et al. 2018, Giovanella et al. 2019). Thus, in nodules with indeterminate cytology, the use of the already known ultrasonographic category to estimate RoM is an available and simple approach.

US is of value in defining the management of patients with thyroid nodules and indeterminate cytology but its role is not consensual. The British Thyroid Association (BTA) (Perros et al. 2014) recommends US in order to rule the need for surgery in patients with B-III cytology (Thy3a). US is also recommended by the American Association of Clinical Endocrinologists (AACE) (Gharib et al. 2016) and Italian Societies (Pacini et al. 2018) in order to rule out the need for surgery in patients with B-III cytology (TIR3A) and only exceptionally in those with B-IV cytology (TIR3B). The American Thyroid Association (ATA) (Haugen et al. 2016) considers US to be of value for the direct indication of surgery in individuals with B-III and B-IV cytology or to rule out its need without molecular tests in those with B-III cytology.

We analyze here the two classifications most used today (ATA (Haugen et al. 2016) and Thyroid Imaging Reporting and Data System (TI-RADS) of the American
C) 2021 Society for Endocrinology Published by Bioscientifica Ltd. Printed in Great Britain 
Table 2 Ultrasonography Classification of the American Thyroid Association (ATA) (Haugen et al. 2016) and Thyroid Imaging Reporting and Data System (TI-RADS) of the American College of Radiology (ACR) (Tessler et al. 2017).

\section{ATA Classification}

High suspicion: Solid hypoechoic nodule or solid hypoechoic component of a partially cystic nodule with one or more of the following features: irregular margins (infiltrative, microlobulated), microcalcifications, taller than wide shape, rim calcifications with small extrusive soft tissue component, evidence of extrathyroidal extension

Intermediate suspicion: Hypoechoic solid nodule with smooth margins without microcalcifications, extrathyroidal extension, or taller than wide shape

Low suspicion: Isoechoic or hyperechoic solid nodule, or partially cystic nodule with eccentric solid areas, without microcalcification, irregular margin or extrathyroidal extension, or taller than wide shape.

Very low suspicion: Spongiform or partially cystic nodules without any of the sonographic features described in low, intermediate or high suspicion patterns Benign: Purely cystic nodules (no solid component)

TI-RADS of the ACR ${ }^{\text {a }}$
TR5: Highly suspicious
( $\geq 7$ points)

TR4: Moderately suspicious (4 to 6 points) TR3: Midly suspicious (3 points)

TR2: Not suspicious (2 points) TR1: Benign (0 point)

aComposition: cystic or almost completely cystic (0 points), spongiform (0 points), mixed cystic and solid (1 point), solid or almost completely solid (2 points); Echogenicity: anechoic (0 points), hyperechoic or isoechoic (1 point), hypoechoic (2 points), very hypoechoic (3 points); Shape: wider-than-tall (0 points), taller-than-wide (3 points); Margin: smooth (0 points), ill-defined (0 points), lobulated or irregular (2 points), extra-thyroidal extension (3 points); Echogenic foci: none or large comet-tail artifacts (0 points), macrocalcifications (1 point), peripheral (rim) calcifications.(2 points), punctate echogenic foci (3 points).

College of Radiology (ACR) (Tessler et al. 2017)) (Table 2), specifically in nodules with indeterminate cytology. The primary goal is to determine whether nodules with highly suspicious US features (or TI-RADS 5) have a RoM that renders prompt surgical indication acceptable and/ or whether nodules with a very low (or TI-RADS 2) or low (TI-RADS 3) ultrasonographic suspicion have a RoM that permits exclusive follow-up of the patient. Thus, additional investigation using more expensive and less accessible methods would be reserved for patients whose clinical, ultrasonographic and cytological data were not sufficient for the definition of management. When molecular tests are easily available, the role of US is less decisive but this method is still important for estimating the pre-test RoM, which influences the negative (NPV) and positive predictive values (PPV) of molecular tests.

In the largest retrospective study that investigated TI-RADS ACR in nodules with indeterminate cytology, Yoo et al. (2020) evaluated 382 nodules with B-III cytology that were subsequently submitted to core needle biopsy (CNB). Final diagnoses of malignancy were confirmed surgically, whereas final diagnoses of benign nodules were determined by surgery or absence of malignancy assessed by CNB and decreased or stable nodule size on US follow-up more than 12 months after initial FNA. The RoM was $8.3 \%, 14.1 \%, 32.2 \%$ and $67.4 \%$ for TI-RADS categories $2(n=12), 3(n=92), 4(n=152)$ and $5(n=126)$, respectively. Three other studies analyzed TI-RADS ACR in a reasonable number of nodules with indeterminate cytology that were removed surgically (104 B-III and 29 B-IV (Sahli et al. 2019), 103 B-III and 99 B-IV (Ahmadi et al.
2019), and 167 B-III (Al Dawish et al. 2020)). In general, these studies showed a RoM $\geq 50 \%$ for TI-RADS 5 nodules, approximately $25 \%$ to $35 \%$ for TI-RADS 4 nodules, and $10 \%$ to 35 for TI-RADS 3 nodules. The RoM was higher for those with B-IV cytology (Ahmadi et al. 2019) and when NIFTP was considered malignant (Sahli et al. 2019). As expected, the number of TI-RADS 2 nodules was small, but the RoM was $12.5 \%(4 / 32)$ when the data of the three studies were pooled.

Three studies, although retrospective, evaluated the ATA classification in a large number of nodules with indeterminate cytology. In the first study, Valderrabano et al. (2018) analyzed ultrasound images of 463 thyroid nodules (38\% B-III and 62\% B-IV) with histological follow-up. Images of all thyroid ultrasounds were independently revised by three observers. Considering NIFTP as malignant, the RoM ranged from $0 \%$ to $5 \%$ for very-low-suspicion nodules, from $20 \%$ to $27 \%$ for low-suspicion nodules, from $14 \%$ to $21 \%$ for intermediate-suspicion nodules, and from $43 \%$ to $51 \%$ for high-suspicion nodules. Considering NIFTP as benign, the differences were even smaller, ranging from $0 \%$ to $5 \%$ for very-low-suspicion nodules, from $10 \%$ to $12 \%$ for low-suspicion nodules, from $8 \%$ to $14 \%$ for intermediate-suspicion nodules, and from $29 \%$ to $41 \%$ for high-suspicion nodules. In the second study, Hong and Lee (2019) analyzed 683 nodules that had B-III cytology after the initial FNA. Nodules were included if they had undergone surgery $(n=421)$, had benign or malignant pathological results on CNB ( $n=35)$, had benign cytology results from more than two FNAs $(n=177)$, or had US https://erc bioscientifica com

https://doi.org/10.1530/ERC-20-0326
(C) 2021 Society for Endocrinology Published by Bioscientifica Ltd. Printed in Great Britain 
follow-up for at least 2 years with a decrease in size and subsequent benign cytology findings $(n=50)$. The RoM of nodules with a very low-, low- intermediate- and highsuspicion US pattern was 0\%, 3.3\%, 33.54\% and 87.67\%, respectively. Finally, in the study of Yoo et al. (2020) described previously and involving 382 nodules with B-III cytology, the RoM for the low-, intermediate- and highsuspicion US categories was $16.3 \%, 36.4 \%$ and $66.1 \%$, respectively.

Some aspects need to be addressed when estimating the RoM of nodules with indeterminate cytology based on US. First, clinical data and cytology findings (whether B-IV or B-III, nature of the atypias in the latter) can modify the estimated RoM for a given ultrasonographic category (Rosario 2014, Ahmadi et al. 2019, Barbosa et al. 2019, Yoo et al. 2020).

Second, studies that evaluate the performance of US include only the subgroup of patients who are submitted to surgery or CNB. It is expected that highly suspicious nodules (or TI-RADS 5) are almost always referred for surgery and the reported RoM should therefore be close to the true risk. However, it is possible that nodules with a very-low/low-suspicion US pattern (or TI-RADS 2 or 3) are referred for surgery when other data are worrisome and the reported RoM may therefore be overestimated. To accurately assess the RoM based on US findings, we conducted a prospective study in which all euthyroid patients with nodules $>1 \mathrm{~cm}$ with an indication for FNA and indeterminate cytology, who were consecutively seen over a given period, were submitted to surgery. Considering NIFTP/TUMP as malignant, the RoM was $10 \%$ for the very low, $13 \%$ for the low, $42.8 \%$ for the intermediate, and 80\% for the high-suspicion categories (Rocha et al. 2018). Using TI-RADS ACR, the RoM was 0\% for TI-RADS $2,14.3 \%$ for TI-RADS 3, 38.8\% for TI-RADS 4 , and 90\% for TI-RADS 5 (Rocha et al. 2019). Considering NIFTP/TUMP as benign, the RoM was $0 \%$ for the very low, $4.3 \%$ for the low, $22.4 \%$ for the intermediate, and $72 \%$ for the high-suspicion categories (Rocha et al. 2018). Using TI-RADS ACR, the RoM was 0\% for TI-RADS 2, 4\% para TI-RADS 3, 22.4\% for TIRADS 4, and 80\% para TI-RADS 5 (Rocha et al. 2019).

Third, recently, tumors considered malignant were reclassified as borderline and these tumors more frequently exhibit indeterminate cytology in FNA (Rosario et al. 2016, 2019). It is therefore important to know whether the RoM considered refers only to malignant tumors or whether it includes borderline tumors and, if so, what is the contribution of the latter. A significant difference is observed especially in nodules with low or intermediate suspicion by ATA or TI-RADS 3 or 4 (Rosario et al. 2016, Rocha et al. 2018, 2019, Valderrabano et al. 2018, Rosario \& Mourão 2019, Sahli et al. 2019). We reported the RoM considering NIFTP to be either benign or malignant because some authors define NIFTP as malignant. However, we believe that the RoM should not include NIFTP.

Fourth, a proportion of thyroid nodules do not meet any of the categories of the ATA classification. In these nodules not classified by ATA and whose cytology was indeterminate, Valderrabano et al. (2018) found a RoM of $29 \%$ to $41 \%$ considering NIFTP as malignant and of $20 \%$ to $21 \%$ considering NIFTP as benign. In the study of Yoo et al. (2020), the RoM was 30\%. Finally, in our prospective study the RoM was $23 \%$ considering NIFTP/ TUMP as malignant and 15.4\% considering NIFTP/TUMP as benign (Rocha et al. 2018). Using TI-RADS, all nodules with indeterminate cytology are classified.

\section{Scintigraphy with 123 or $99 \mathrm{mTc}$}

There is consensus that autonomous nodules have a low RoM (Perros et al. 2014, Gharib et al. 2016, Haugen et al. 2016, Russ et al. 2017, Pacini et al. 2018, Hoang et al. 2019, Giovanella et al. 2019). Scintigraphy with ${ }^{123}$ I or $99 \mathrm{~m}$ Tc might be indicated for individuals with thyroid nodules in three situations. This method is recommended in patients with low TSH (Perros et al. 2014, Gharib et al. 2016, Haugen et al. 2016, Russ et al. 2017, Pacini et al. 2018, Hoang et al. 2019, Giovanella et al. 2019), even if they are asymptomatic and have normal free T4 and T3 concentrations. Many authors even recommend this method in euthyroid individuals with TSH in the lower half of the reference range, especially in iodine-deficient regions (Gharib et al. 2016, Russ et al. 2017, Giovanella et al. 2019). With this management, it is believed that part of the nodules with an indication for FNA based on US may not require this procedure because scintigraphy reveals hyperuptake (Schenke et al. 2019, Castellana et al. 2020, Noto et al. 2020). Finally, the indication that interests us here are euthyroid patients with nodules $>1$ $\mathrm{cm}$ whose cytology was indeterminate.

In the last situation, the AACE (Gharib et al. 2016) recognizes the value of scintigraphy in iodine-deficient regions and when the TSH level is low-normal (e.g. 0.5-1.0 mIU/L). The European Association of Nuclear Medicine (EANM) and the Society of Nuclear Medicine and Molecular Imaging (SNMMI) (Giovanella et al. 2019) recommend that, to identify a benign autonomously https://erc bioscientifica com https://doi.org/10.1530/ERC-20-0326 (c) 2021 Society for Endocrinology Published by Bioscientifica Ltd. Printed in Great Britain 
functioning thyroid nodule (including 'compensated' ones), it is reasonable to first perform thyroid scintigraphy (if not previously obtained), particularly if TSH is in the lower end of the normal range (e.g. less than $1.5 \mathrm{mU} / \mathrm{L}$ ) and to select only patients with nonfunctioning nodules for molecular testing, molecular imaging, or diagnostic lobectomy.

In a prospective study on 77 euthyroid patients with nodules $>1 \mathrm{~cm}$ without highly suspicious US features and with cytology suggesting 'follicular neoplasm', radioiodine scintigraphy revealed hyperuptake in the topography of the nodule in 36 patients (46.5\%) and none of these nodules was malignant (Rosario et al. 2010). Another prospective study evaluated 78 euthyroid patients with 84 nodules $>1 \mathrm{~cm}$ with indeterminate cytology that were not very suspicious on US (Rosario et al. 2018). Hyperuptake of ${ }^{123}$ I in the area corresponding to the nodule was detected in 19 patients (24\%) and 21 nodules (25\%). Of these, 20 were benign and there was one borderline tumor.

However, the probability of scintigraphy showing that hyperuptake in the nodule is inversely correlated with TSH concentrations, which is unlikely in patients with TSH $>2 \mathrm{mIU} / \mathrm{L}$, is much higher in those with TSH $<1$ $\mathrm{mIU} / \mathrm{L}$ (Rosario et al. 2018). The relationship between RoM and serum TSH in euthyroid individuals with cytologically indeterminate nodules corroborates this observation. A recent study showed that among 378 euthyroid patients the RoM was $9.8 \%$ for TIR3A nodules and $27.3 \%$ for TIR3B nodules (Cappelli et al. 2020). However, in the subgroup with TSH in the lower quartile $(0.4-1.42 \mathrm{mIU} / \mathrm{L})$, the RoM was significantly lower, $5.9 \%$ for TIR3A and $12 \%$ for TIR3B (Cappelli et al. 2020), possibly reflecting a higher probability of the nodules being autonomous in this TSH quartile.

\section{F-fluorodeoxyglucose positron emission tomography}

The EANM and SNMI (Giovanella et al. 2019) recommend molecular thyroid imaging using 18FDG. A nodule characterized by low or absent ${ }^{18}$ FDG uptake is considered at a very low RoM. According to these societies, the high NPV of thyroid imaging with ${ }^{18} \mathrm{FDG}$ is very helpful in characterizing nodules with indeterminate cytological results.

The EANM and SNMI (Giovanella et al. 2019) consider that any focal uptake above normal thyroid parenchyma, corresponding to the nodule with cytological indeterminate results, is considered as positive.
Thus, the sensitivity of ${ }^{18} \mathrm{FDG}-\mathrm{PET}$ in identifying malignant tumors $>1 \mathrm{~cm}$ is high (Kresnik et al. 2003, Kim et al. 2007, Sebastianes et al. 2007, Traugott et al. 2010, Muñoz Pérez et al. 2013, Buyukdereli et al. 2016, Pathak et al. 2016, Piccardo et al. 2016, Rosario et al. 2019, Piccardo et al. 2020).

As observed for molecular tests, the pre-test RoM can influence the NPV of ${ }^{18} \mathrm{FDG}$-PET. In this regard, US can be important. In the study of Deandreis et al. (2012), among 26 nodules without ${ }^{18}$ FDG uptake, $0 / 21$ benign or only suspicious on US vs $2 / 5$ malignant on US were cancer. Considering TUMP/cancer, there were $2 / 21$ vs $3 / 5$, respectively. In the series of Merten et al. (2017), among $20{ }^{18} \mathrm{FDG}$-negative nodules, $1 / 16$ with a very-low-, low- or intermediate-suspicion US pattern vs $1 / 4$ highly suspicious nodules were cancer. In another prospective study that intentionally excluded nodules with highly suspicious US features, of the $32{ }^{18} \mathrm{FDG}$-negative nodules, 30 were benign $(93.8 \%), 2$ were NIFTP/TUMP (6.2\%), and none was cancer (Rosario et al. 2019). Thus, when the clinical, ultrasonographic and cytological data do not suggest a very high RoM, the absence of nodular uptake on ${ }^{18}$ FDG-PET has a sufficient NPV for macrocarcinoma to rule out the need for surgery.

Some factors influence the specificity of ${ }^{18} \mathrm{FDG}-\mathrm{PET}$, which is higher when the maximum SUV is $>5$ (Kresnik et al. 2003, Mitchell et al. 2005, de Geus-Oei et al. 2006, Kim et al. 2007, Sebastianes et al. 2007, Smith et al. 2008, Traugott et al. 2010, Deandreis et al. 2012, Muñoz Pérez et al. 2013, Pathak et al. 2016, Merten et al. 2017, Nguyen et al. 2018, Rosario et al. 2019, Piccardo et al. 2020) and lower in nodules with cytology with predominance of oxyphilic cells or suspicious for Hürthle cells neoplasm (Kresnik et al. 2003, de Geus-Oei et al. 2006, Deandreis et al. 2012, Muñoz Pérez et al. 2013, Pathak et al. 2016). Depending on the clinical context (considering pre-test RoM and maximum SUV) and availability of molecular tests, a positive 18FDG-PET scan does not necessarily represent an indication for surgery. The patient can still be submitted to molecular tests and thyroidectomy can be excluded if these tests suggest benignity.

\section{Other accessible imaging methods}

Although assessment of vascularization of the nodule is recommended, using US/Doppler, the ATA classification (Haugen et al. 2016) or TI-RADS (Russ et al. 2017, Tessler et al. 2017) does not consider this parameter in the definition of the level of suspicion for malignancy. 
Table 3 Main advantages and limitations of the most accessible and useful imaging methods for thyroid nodules $>1 \mathrm{~cm}$ with indeterminate cytology.

\begin{tabular}{|c|c|}
\hline Imaging method & Advantages \\
\hline Ultrasonography & $\begin{array}{l}\text { Wide availability, low cost, extensively studied, } \\
\text { permits to obtain additional features of the nodule } \\
\text { (Doppler, elastography), good predictive value for } \\
\text { the extreme categories of suspicion of malignancy }\end{array}$ \\
\hline $\begin{array}{l}\text { Scintigraphy with }{ }^{123 \mid} \\
\text { or } 99 \mathrm{mTC}\end{array}$ & $\begin{array}{l}\text { Easy accessibility, affordable cost, high negative } \\
\text { predictive value for hyperuptake in the } \\
\text { topography of the nodule }\end{array}$ \\
\hline 18FDG-PET & $\begin{array}{l}\text { More accessible and less expensive than high- } \\
\text { performance molecular tests, high negative } \\
\text { predictive value for the absence of }{ }^{18 F D G ~ u p t a k e ~} \\
\text { in the topography of the nodule }\end{array}$ \\
\hline
\end{tabular}

\section{Limitations \\ Dependence on operator, contributes little to the category of intermediate suspicion of malignancy}

Probability of revealing nodular hyperuptake is inversely correlated with serum TSH, which is unlikely if TSH > 1.5-2 mIU/L; 'inconclusive' results are not uncommon; low positive predictive value for nodular hypouptake High cost, low positive predictive value (except for non-Hürthle cell cytology and high SUVmax)
Analyzed separately, the vascularization pattern seems to be of value for defining the benign or malignant nature of nodules with indeterminate cytology (Iared et al. 2010), but there is little information about the frequency at which Doppler diverges from US (B-mode) in terms of the suspicion for malignancy and if the RoM estimated by US is indeed modified by the Doppler result in these cases. Regarding this additional value, a prospective study specifically investigating nodules with indeterminate cytology showed a modest increase in the sensitivity of the ATA ultrasonographic classification with the addition of Doppler to US (B-mode) (Rocha et al. 2018).

The elasticity of the nodule (elastography) has also been studied. Elastography has many limitations and cannot reliably be applied to large nodules $(>3 \mathrm{~cm})$, nodules with macrocalcifications, cystic, deeply located and/or isthmic nodules, nodules located near the carotid artery, or coalescent nodules (Russ et al. 2017). The capacity of elastography to define the nature of nodules with indeterminate cytology is controversial (Trimboli et al. 2015, Bardet et al. 2017). Rather than its individual value, it is more important to know the frequency at which elastography reveals a level of suspicion for malignancy that differs from that estimated by US (B-mode) and to what extent this level is modified by elastography. Regarding this additional value of elastography specifically in nodules with indeterminate cytology, the results are not uniform (Trimboli et al. 2015, Cantisani et al. 2016, Bardet et al. 2017, Azizi et al. 2018, Gay et al. 2018, Liu et al. 2018, Ríos et al. 2018). If obtained, elevated stiffness on elastography is considered a suspicious finding for malignancy but it must be remembered that readings may be low in non-papillary thyroid carcinomas.

There is currently no recommendation for the use of CT or MRI in nodules with indeterminate cytology in order to define their nature (Hoang et al. 2019). These methods can be useful if there is a gross invasion or metastatic disease, if the nodule is part of a goiter that is suspected to extend substernally, or in the case of a suspicion of invasive thyroid cancer (Hoang et al. 2019).

The EANM and SNMI (Giovanella et al. 2019) consider molecular thyroid imaging using $99 \mathrm{mTc}$-MIBI of value but this method (i) requires semiquantitative evaluation (using retention index, washout index) to optimize its sensitivity (Saggiorato et al. 2009, Campennì et al. 2016, Giovanella et al. 2016, 2019), (ii) possesses few studies that include a considerable number of patients specifically with nodules with indeterminate cytology (Campennì et al. 2016, Giovanella et al. 2016, Piccardo et al. 2016), and (iii) exhibited lower sensitivity and NPV than ${ }^{18}$ FDGPET in the only direct comparative study (Piccardo et al. 2016).

Table 3 shows the main advantages and limitations of accessible imaging methods that are apparently more useful for the definition of the nature of $\mathrm{TN}>1 \mathrm{~cm}$ with indeterminate cytology.

\section{Conclusions}

Regarding the usefulness of accessible imaging methods in euthyroid individuals with nodules $>1 \mathrm{~cm}$ with an indication of FNA and indeterminate cytology (B-III (Thy3a, TIR3A) or B-IV (Thy3f, TIR3B)), we conclude that:

- In the case of nodules with a high suspicion US pattern (or TI-RADS 5), the RoM supports surgical indication even in the absence of additional tests. The same applies to nodules with an intermediate suspicion (or TI-RADS 4) but elevated stiffness on elastography (if obtained). 
- In nodules with low-risk indeterminate cytology and low-suspicion appearance (or TI-RADS $\leq 3$ ) on US and elastography (if obtained), follow-up is acceptable even without additional tests. Although less consistent, this recommendation may be valid for nodules with highrisk indeterminate cytology (TIR 3B) and with a verylow-suspicion appearance (or TI-RADS 2) on US and elastography (if obtained).

- In patients with TSH $<1-1.5 \mathrm{mIU} / \mathrm{L}$ and nodules without a highly suspicious US pattern (or TI-RADS 5), scintigraphy with ${ }^{123}$ I can be obtained to rule out hyperfunctioning nodules before requesting diagnostic methods that are more expensive and less accessible.

- In the case of nodules that are not very suspicious on US, ${ }^{18}$ FDG-PET can be obtained and, if it does not reveal nodular uptake, the risk of the nodule corresponding to a macrocarcinoma is sufficiently low to allow follow-up. The PPV of focal nodular uptake on ${ }^{18 F D G-}$ PET depends on the pre-test RoM, cytological findings, and maximum SUV.

- There is currently no evidence for the use of CT, MRI

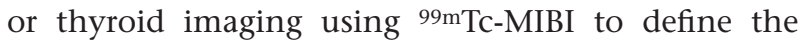
nature of cytologically indeterminate nodules.

\section{Declaration of interest}

The authors declare that there is no conflict of interest that could be perceived as prejudicing the impartiality of this review.

\section{Funding}

This work did not receive any specific grant from any funding agency in the public, commercial or not-for-profit sector.

\section{Author contribution statement}

Study design: All authors. Study conduct: All authors. Data management: All authors. Data analysis: All authors. Data interpretation: All authors. Manuscript writing: All authors. Manuscript review and approval: All authors.

\section{References}

Ahmadi S, Herbst R, Oyekunle T, Jiang X, Strickland K, Roman S \& Sosa JA 2019 Using the ATA and ACR TI-RADS sonographic classifications as adjunctive predictors of malignancy for indeterminate thyroid nodules. Endocrine Practice 25 908-917. (https://doi.org/10.4158/EP-2018-0559)

Al Dawish M, Alwin Robert A, Al Shehri K, Hawsawi S, Mujammami M, Al Basha IA, Alrasheed M, Asiri S, Alzouman M \& Alkharashi E 2020 Risk stratification of thyroid nodules with Bethesda III category: the experience of a territorial healthcare hospital. Cureus 12 e8202. (https://doi.org/10.7759/cureus.8202)
Ali SZ \& Cibas ES 2018 The Bethesda System for Reporting Thyroid Cytopathology, 2nd ed. New York: Springer.

Azizi G, Keller JM, Mayo ML, Piper K, Puett D, Earp KM \& Malchoff CD 2018 Shear wave elastography and Afirma ${ }^{\mathrm{TM}}$ gene expression classifier in thyroid nodules with indeterminate cytology: a comparison study. Endocrine 59 573-584. (https://doi.org/10.1007/ s12020-017-1509-9)

Barbosa TLM, Junior COM, Graf H, Cavalvanti T, Trippia MA, da Silveira Ugino RT, de Oliveira GL, Granella VH \& de Carvalho GA 2019 ACR TI-RADS and ATA US scores are helpful for the management of thyroid nodules with indeterminate cytology. BMC Endocrine Disorders 19 112. (https://doi.org/10.1186/s12902-0190429-5)

Bardet S, Ciappuccini R, Pellot-Barakat C, Monpeyssen H, Michels JJ, Tissier F, Blanchard D, Menegaux F, de Raucourt D, Lefort M, et al. 2017 Shear wave elastography in thyroid nodules with indeterminate cytology: results of a prospective bicentric study. Thyroid $\mathbf{2 7}$ 1441-1449. (https://doi.org/10.1089/thy.2017.0293)

Buyukdereli G, Aktar Y, Kara E, Uguz A \& Sonmez H 2016 Role of 18F-fluorodeoxyglucose positron emission tomography/computed tomography in the evaluation of cytologically indeterminate thyroid nodules. Iranian Journal of Radiology 13 e21186. (https://doi. org/10.5812/iranjradiol.21186)

Campennì A, Giovanella L, Siracusa M, Alibrandi A, Pignata SA, Giovinazzo S, Trimarchi F, Ruggeri RM \& Baldari S 2016 (99m) Tc-methoxy-isobutyl-isonitrile scintigraphy is a useful tool for assessing the risk of malignancy in thyroid nodules with indeterminate fine-needle cytology. Thyroid 26 1101-1109. (https:// doi.org/10.1089/thy.2016.0135)

Cantisani V, Maceroni P, D'Andrea V, Patrizi G, Di Segni M, De Vito C, Grazhdani H, Isidori AM, Giannetta E, Redler A, et al. 2016 Strain ratio ultrasound elastography increases the accuracy of colourDoppler ultrasound in the evaluation of Thy-3 nodules. A bi-centre university experience. European Radiology 26 1441-1449. (https://doi. org/10.1007/s00330-015-3956-0)

Cappelli C, Pirola I, Gandossi E, Rotondi M, Lombardi D, Casella C, Marini F, Saullo M, Agosti B, Di Lodovico E, et al. 2020 Could serum TSH levels predict malignancy in euthyroid patients affected by thyroid nodules with indeterminate cytology? International Journal of Endocrinology 2020 7543930. (https://doi.org/10.1155/2020/7543930)

Castellana M, Virili C, Paone G, Scappaticcio L, Piccardo A, Giovanella L \& Trimboli P 2020 Ultrasound systems for risk stratification of thyroid nodules prompt inappropriate biopsy in autonomously functioning thyroid nodules. Clinical Endocrinology 93 67-75. (https://doi.org/10.1111/cen.14204)

de Geus-Oei LF, Pieters GF, Bonenkamp JJ, Mudde AH, BleekerRovers CP, Corstens FH \& Oyen WJ 2006 18F-FDG PET reduces unnecessary hemithyroidectomies for thyroid nodules with inconclusive cytologic results. Journal of Nuclear Medicine $\mathbf{4 7}$ 770-775.

Deandreis D, Al Ghuzlan A, Auperin A, Vielh P, Caillou B, Chami L, Lumbroso J, Travagli JP, Hartl D, Baudin E, et al. 2012 Is (18) F-fluorodeoxyglucose-PET/CT useful for the presurgical characterization of thyroid nodules with indeterminate fine needle aspiration cytology? Thyroid 22 165-172. (https://doi.org/10.1089/ thy.2011.0255)

Gay S, Schiaffino S, Santamorena G, Massa B, Ansaldo G, Turtulici G, Giusti M \& at the Policlinico San Martino, Genoa TT 2018 Role of strain elastography and shear-wave elastography in a multiparametric clinical approach to indeterminate cytology thyroid nodules. Medical Science Monitor 24 6273-6279. (https://doi. org/10.12659/MSM.909870)

Gharib H, Papini E, Garber JR, Duick DS, Harrell RM, Hegedüs L, Paschke R, Valcavi R, Vitti P \& AACE/ACE/AME Task Force on Thyroid Nodules 2016 American Association of Clinical Endocrinologists, American College of Endocrinology, and (c) 2021 Society for Endocrinology Published by Bioscientifica Ltd. Printed in Great Britain 
Associazione Medici Endocrinologi Medical Guidelines for clinical practice for the diagnosis and management of thyroid nodules 2016 update. Endocrine Practice 22 622-639. (https://doi.org/10.4158/ EP161208.GL)

Giovanella L, Campenni A, Treglia G, Verburg FA, Trimboli P, Ceriani L \& Bongiovanni M 2016 Molecular imaging with (99m)Tc-MIBI and molecular testing for mutations in differentiating benign from malignant follicular neoplasm: a prospective comparison. European Journal of Nuclear Medicine and Molecular Imaging 43 1018-1026. (https://doi.org/10.1007/s00259-015-3285-1)

Giovanella L, Avram AM, Iakovou I, Kwak J, Lawson SA, Lulaj E, Luster M, Piccardo A, Schmidt M, Tulchinsky M, et al. 2019 EANM practice guideline/SNMMI procedure standard for RAIU and thyroid scintigraphy. European Journal of Nuclear Medicine and Molecular Imaging 46 2514-2525. (https://doi.org/10.1007/s00259-019-04472-8)

Haugen BR, Alexander EK, Bible KC, Doherty GM, Mandel SJ, Nikiforov YE, Pacini F, Randolph GW, Sawka AM \& Schlumberger M 20162015 American Thyroid Association Management Guidelines for adult patients with thyroid nodules and differentiated thyroid cancer: the American Thyroid Association Guidelines task force on thyroid nodules and differentiated thyroid cancer. Thyroid 26 1-133. (https://doi.org/10.1089/thy.2015.0020)

Hoang JK, Oldan JD, Mandel SJ, Policeni B, Agarwal V, Burns J, Bykowski J, Harvey HB, Juliano AF, Kennedy TA, et al. 2019 ACR appropriateness criteria(®) thyroid disease. Journal of American College of Radiology 16 S300-S314. (https://doi.org/10.1016/j.jacr.2019.02.004)

Hong HS \& Lee JY 2019 Diagnostic performance of ultrasound patterns by K-TIRADS and 2015 ATA guidelines in risk stratification of thyroid nodules and follicular lesions of undetermined significance. American Journal of Roentgenology 213 444-450. (https://doi. org/10.2214/AJR.18.20961)

Iared W, Shigueoka DC, Cristófoli JC, Andriolo R, Atallah AN, Ajzen SA \& Valente O 2010 Use of color Doppler ultrasonography for the prediction of malignancy in follicular thyroid neoplasms: systematic review and meta-analysis. Journal of Ultrasound in Medicine 29 419-425. (https://doi.org/10.7863/jum.2010.29.3.419)

Kim JM, Ryu JS, Kim TY, Kim WB, Kwon GY, Gong G, Moon DH, Kim SC, Hong SJ \& Shong YK 2007 18F-fluorodeoxyglucose positron emission tomography does not predict malignancy in thyroid nodules cytologically diagnosed as follicular neoplasm. Journal of Clinical Endocrinology and Metabolism 92 1630-1634. (https://doi. org/10.1210/jc.2006-2311)

Kresnik E, Gallowitsch HJ, Mikosch P, Stettner H, Igerc I, Gomez I, Kumnig G \& Lind P 2003 Fluorine-18-fluorodeoxyglucose positron emission tomography in the preoperative assessment of thyroid nodules in an endemic goiter area. Surgery 133 294-299. (https://doi. org/10.1067/msy.2003.71)

Liu JF, Chen YX, Zheng YJ, Wen DH, Wang YC \& Xue G 2018 The role of SWE and ATA (2015) guidelines combined mode in differentiation malignant from benign of Bethesda III thyroid nodules. Lin Chuang Er Bi Yan Hou Tou Jing Wai Ke za Zhi 32 1400-1405. (https://doi. org/10.13201/j.issn.1001-1781.2018.18.009)

Merten MM, Castro MR, Zhang J, Durski J \& Ryder M 2017 Examining the role of preoperative positron emission tomography/computerized tomography in combination with ultrasonography in discriminating benign from malignant cytologically indeterminate thyroid nodules. Thyroid 27 95-102. (https://doi.org/10.1089/thy.2016.0379)

Mitchell JC, Grant F, Evenson AR, Parker JA, Hasselgren PO \& Parangi S 2005 Preoperative evaluation of thyroid nodules with 18FDG-PET/ CT. Surgery 138 1166-1174; discussion 1174. (https://doi. org/10.1016/j.surg.2005.08.031)

Muñoz Pérez N, Villar del Moral JM, Muros Fuentes MA, López de la Torre M, Arcelus Martínez JI, Becerra Massare P, Esteva Martínez D, Cañadas Garre M, Coll Del Rey E, Bueno Laraño P, et al. 2013 Could 18F-FDG-PET/CT avoid unnecessary thyroidectomies in patients with cytological diagnosis of follicular neoplasm? Langenbeck's Archives of Surgery 398 709-716. (https://doi.org/10.1007/s00423-013-1070-9)

Nguyen TT, Lange NGE, Nielsen AL, Thomassen A, Døssing H, Godballe C \& Rohde M 2018 PET/CT and prediction of thyroid cancer in patients with follicular neoplasm or atypia. European Archives of Oto-Rhino-Laryngology 275 2109-2117. (https://doi. org/10.1007/s00405-018-5030-4)

Noto B, Eveslage M, Pixberg M, Gonzalez Carvalho JM, Schäfers M, Riemann B \& Kies P 2020 Prevalence of hyperfunctioning thyroid nodules among those in need of fine needle aspiration cytology according to ATA 2015, EU-TIRADS, and ACR-TIRADS. European Journal of Nuclear Medicine and Molecular Imaging 47 1518-1526. (https://doi.org/10.1007/s00259-020-04740-y)

Pacini F, Basolo F, Bellantone R, Boni G, Cannizzaro MA, De Palma M, Durante C, Elisei R, Fadda G, Frasoldati A, et al. 2018 Italian consensus on diagnosis and treatment of differentiated thyroid cancer: joint statements of six Italian societies. Journal of Endocrinological Investigation 41 849-876. (https://doi.org/10.1007/ s40618-018-0884-2)

Pathak KA, Goertzen AL, Nason RW, Klonisch T \& Leslie WD 2016 A prospective cohort study to assess the role of FDG-PET in differentiating benign and malignant follicular neoplasms. Annals of Medicine and Surgery 12 27-31. (https://doi.org/10.1016/j. amsu.2016.10.008)

Perros P, Boelaert K, Colley S, Evans C, Evans RM, Gerrard Ba G, Gilbert J, Harrison B, Johnson SJ, Giles TE, et al. 2014 Guidelines for the management of thyroid cancer British Thyroid Association. Clinical Endocrinology 81 (Supplement 1) 1-122. (https://doi. org/10.1111/cen.12515)

Piccardo A, Puntoni M, Treglia G, Foppiani L, Bertagna F, Paparo F, Massollo M, Dib B, Paone G, Arlandini A, et al. 2016 Thyroid nodules with indeterminate cytology: prospective comparison between 18F-FDG-PET/CT, multiparametric neck ultrasonography, 99mTc-MIBI scintigraphy and histology. European Journal of Endocrinology 174 693-703. (https://doi.org/10.1530/EJE-15-1199)

Piccardo A, Puntoni M, Dezzana M, Bottoni G, Foppiani L, Marugo A, Catrambone U, Ugolini M, Sola S, Gatto M, et al. 2020 Indeterminate thyroid nodules. The role of (18)F-FDG PET/CT in the 'era' of ultrasonography risk stratification systems and new thyroid cytology classifications. Endocrine. (https://doi.org/10.1007/s12020020-02239-y)

Ríos A, Rodríguez JM, Torregrosa NM, Torregrosa B, Cepero A, Abellán MD, Hernández AM \& Parrilla P 2018 Evaluation of the thyroid nodule with high-resolution ultrasonography and elastography without fine needle aspiration biopsy. Medicina Clinica 151 89-96. (https://doi.org/10.1016/j.medcli.2017.09.016)

Rocha TG, Rosario PW, Silva AL, Nunes MB, Silva TH, de Oliveira PHL \& Calsolari MR 2018 Ultrasonography classification of the American Thyroid Association for predicting malignancy in thyroid nodules $>1 \mathrm{~cm}$ with indeterminate cytology: a prospective study. Hormone and Metabolic Research 50 597-601. (https://doi. org/10.1055/a-0655-3016)

Rocha TG, Rosario PW, Silva AL, Nunes MB \& Calsolari MR 2019 Thyroid imaging reporting and data system (TI-RADS) of the American College of Radiology (ACR) for predicting malignancy in thyroid nodules $>1 \mathrm{~cm}$ with indeterminate cytology. Diagnostic Cytopathology 47 523-525. (https://doi.org/10.1002/dc.24119)

Rosario PW 2014 Thyroid nodules with atypia or follicular lesions of undetermined significance (Bethesda Category III): importance of ultrasonography and cytological subcategory. Thyroid 24 1115-1120. (https://doi.org/10.1089/thy.2013.0650)

Rosario PW \& Mourão GF 2019 Noninvasive follicular thyroid neoplasm with papillary-like nuclear features (NIFTP): a review for clinicians. Endocrine-Related Cancer 26 R259-R266. (https://doi.org/10.1530/ ERC-19-0048)
C) 2021 Society for Endocrinology Published by Bioscientifica Ltd. Printed in Great Britain 
Rosario PW, Salles DS, Bessa B \& Purisch S 2010 Contribution of scintigraphy and ultrasonography to the prediction of malignancy in thyroid nodules with indeterminate cytology. Arquivos Brasileiros de Endocrinologia e Metabologia 54 56-59. (https://doi.org/10.1590/ s0004-27302010000100010)

Rosario PW, Mourão GF, Nunes MB, Nunes MS \& Calsolari MR 2016 Noninvasive follicular thyroid neoplasm with papillary-like nuclear features. Endocrine-Related Cancer 23 893-897. (https://doi. org/10.1530/ERC-16-0379)

Rosario PW, Rocha TG, Mourão GF \& Calsolari MR 2018 Is radioiodine scintigraphy still of value in thyroid nodules with indeterminate cytology? A prospective study in an iodine-sufficient area. Nuclear Medicine Communications 39 1059-1060. (https://doi.org/10.1097/ MNM.0000000000000896)

Rosario PW, Rocha TG \& Calsolari MR 2019 Fluorine-18fluorodeoxyglucose positron emission tomography in thyroid nodules with indeterminate cytology: a prospective study. Nuclear Medicine Communications 40 185-187. (https://doi.org/10.1097/ MNM.0000000000000946)

Russ G, Bonnema SJ, Erdogan MF, Durante C, Ngu R \& Leenhardt L 2017 European Thyroid Association guidelines for ultrasound malignancy risk stratification of thyroid nodules in adults: the EU-TIRADS. European Thyroid Journal 6 225-237. (https://doi. org/10.1159/000478927)

Saggiorato E, Angusti T, Rosas R, Martinese M, Finessi M, Arecco F, Trevisiol E, Bergero N, Puligheddu B, Volante M, et al. 2009 99mTcMIBI Imaging in the presurgical characterization of thyroid follicular neoplasms: relationship to multidrug resistance protein expression. Journal of Nuclear Medicine 50 1785-1793. (https://doi.org/10.2967/ jnumed.109.064980)

Sahli ZT, Karipineni F, Hang JF, Canner JK, Mathur A, Prescott JD, Sheth S, Ali SZ \& Zeiger MA 2019 The association between the ultrasonography TIRADS classification system and surgical pathology among indeterminate thyroid nodules. Surgery 165 69-74. (https:// doi.org/10.1016/j.surg.2018.04.094)

Schenke S, Seifert P, Zimny M, Winkens T, Binse I \& Görges R 2019 Risk stratification of thyroid nodules using the thyroid imaging reporting and data system (TIRADS): the omission of thyroid scintigraphy increases the rate of falsely suspected lesions. Journal of Nuclear Medicine 60 342-347. (https://doi.org/10.2967/ jnumed.118.211912)

Sebastianes FM, Cerci JJ, Zanoni PH, Soares J Jr, Chibana LK, Tomimori EK, de Camargo RY, Izaki M, Giorgi MC, Eluf-Neto J, et al. 2007 Role of 18F-fluorodeoxyglucose positron emission tomography in preoperative assessment of cytologically indeterminate thyroid nodules. Journal of Clinical Endocrinology and Metabolism 92 4485-4488. (https://doi.org/10.1210/jc.2007-1043)

Smith RB, Robinson RA, Hoffman HT \& Graham MM 2008 Preoperative FDG-PET imaging to assess the malignant potential of follicular neoplasms of the thyroid. Otolaryngology-Head and Neck Surgery 138 101-106. (https://doi.org/10.1016/j.otohns.2007.09.008)

Tessler FN, Middleton WD, Grant EG, Hoang JK, Berland LL, Teefey SA, Cronan JJ, Beland MD, Desser TS, Frates MC, et al. 2017 ACR thyroid imaging, reporting and data system (TI-RADS): white paper of the ACR TI-RADS Committee. Journal of the American College of Radiology 14 587-595. (https://doi.org/10.1016/j.jacr.2017.01.046)

Traugott AL, Dehdashti F, Trinkaus K, Cohen M, Fialkowski E, Quayle F, Hussain H, Davila R, Ylagan L \& Moley JF 2010 Exclusion of malignancy in thyroid nodules with indeterminate fine-needle aspiration cytology after negative 18F-fluorodeoxyglucose positron emission tomography: interim analysis. World Journal of Surgery 34 1247-1253. (https://doi.org/10.1007/s00268-010-0398-3)

Trimboli P, Treglia G, Sadeghi R, Romanelli F \& Giovanella L 2015 Reliability of real-time elastography to diagnose thyroid nodules previously read at FNAC as indeterminate: a meta-analysis. Endocrine 50 335-343. (https://doi.org/10.1007/s12020-014-0510-9)

Valderrabano P, McGettigan MJ, Lam CA, Khazai L, Thompson ZJ, Chung CH, Centeno BA \& McIver B 2018 Thyroid nodules with indeterminate cytology: utility of the American Thyroid Association sonographic patterns for cancer risk stratification. Thyroid $\mathbf{2 8}$ 1004-1012. (https://doi.org/10.1089/thy.2018.0085)

Yoo WS, Ahn HY, Ahn HS, Chung YJ, Kim HS, Cho BY, Seo M, Moon JH \& Park YJ 2020 Malignancy rate of Bethesda category III thyroid nodules according to ultrasound risk stratification system and cytological subtype. Medicine 99 e18780. (https://doi.org/10.1097/ MD.0000000000018780)

Received in final form 28 October 2020

Accepted 6 November 2020

Accepted Manuscript published online 6 November 2020 (c) 2021 Society for Endocrinology Published by Bioscientifica Ltd. Printed in Great Britain 